\title{
Da ilegalidade à certificação florestal: estudo de caso do manejo florestal comunitário no Baixo Amazonas
}

\author{
From illegality to forest certification: case study of community based forest \\ management in Down Amazonas
}

Philippe Waldhoff ${ }^{\mathrm{I}}$, Edson Vidal "I

\begin{abstract}
Resumo
Este artigo analisa as mudanças no arranjo produtivo da madeira oriunda da extração comunitária, no município de Boa Vista do Ramos - Amazonas, decorrentes das alterações nas políticas ambientais e normas voltadas ao manejo florestal sustentável. Trata-se de uma pesquisa descritiva baseada em um estudo de caso desenvolvido a partir de observação participante e entrevistas não estruturadas, realizados entre 1999 e 2007, período de contato direto com uma associação de produtores florestais e o ambiente. Foram verificados documentos relacionados à formalização e legalização das atividades e realizada uma revisão sobre as políticas e normas voltadas ao manejo florestal. A análise dos dados se deu a partir de 2011. Os resultados demonstram que os extratores de madeira, que desenvolviam suas atividades de maneira tradicional, tiveram de se adaptar às novas orientações políticas e técnicas. Houve uma mudança de um padrão de produção informal e ilegal para o manejo florestal comunitário juridicamente institucionalizado sob a forma de associação, com licença ambiental e certificação florestal. A coerção da sociedade visando à diminuição do desmatamento na Amazônia e o desenvolvimento de um ambiente favorável ao manejo florestal comunitário podem ser considerados como causas desta mudança. O conhecimento tradicional aliado ao técnico-científico foi o que possibilitou o desenvolvimento de um projeto de referência para a região. Por fim, a falta de estratégias específicas para o empoderamento dos manejadores florestais aliado a mudanças nas políticas públicas pode ter levado à busca por arranjos produtivos mais simples, mudando a orientação do manejo florestal de comunitário para o individual/familiar.
\end{abstract}

Palavras-chave: Floresta amazônica; Comunidades tradicionais; Adequação ambiental; Legislação florestal

\begin{abstract}
This paper analyses changes on the arrangements of wood production from community forestry in Boa Vista do Ramos - Amazonas, resulting from alterations in environmental policies and sustainable forest management regulations. We present a descriptive research based in a case study and carried out through participant observation and non-structured interviews during a period with direct contact with a forestry association and the environment. Documents related to the formalization and legalization of the activity were analyzed and a review in policies and regulation related to forest management was made. Results demonstrated that the wood extractors, who used to develop their activities traditionally, had to adapt to new policy and technical orientations. There were changes in the illegal and informal pattern of production to a formalized, licensed and certificated community-based forest management. The coercion of the society to reduce the deforestation in Amazonia state and the development of a favorable situation to community forestry could be considered as causes of these changes. Traditional ecological knowledge allied with technical and scientific knowledge allowed the development of a reference project to the region. At last, the lack of specific strategies to the empowerment of the forest managers and changes in public policies could have led the search for simple productive arrangements, changing from community forestry to individual/familiar scale projects.
\end{abstract}

Keywords: Amazon forest; Traditional communities; Environmental regulation; Forestry legislation

\footnotetext{
Engenheiro Florestal, Dr., Professor Titular do Instituto Federal do Amazonas, Campus Manaus Zona Leste, Av. Cosme Ferreira, 8045, CEP 69086475, Manaus (AM), Brasil. philippe.waldhoff@ifam.edu.br (ORCID: 0000-0001-6864-2315)

Engenheiro Agrônomo, Dr., Professor do Departamento de Ciências Florestais, ESALQ, Universidade de São Paulo, Av. Pádua Dias, 11, CEP 13418900, Piracicaba (SP), Brasil. edson.vidal@usp.br (ORCID: 0000-0002-8028-6998)
} 


\section{Introdução}

A exploração das florestas primitivas da bacia amazônica ficou proibida a partir do Código Florestal de 1965, que só permitiu o seu uso por meio de planos técnicos de condução e manejo (BRASIL, 2007). De acordo com Siry et al. (2005), foi a partir da Conferência das Nações Unidas para o Meio Ambiente e Desenvolvimento (CNUMAD) que passaram a ser desenvolvidos critérios e indicadores regionais e internacionais para medir e monitorar o sucesso no alcance do manejo florestal sustentável. No Brasil, a regulamentação sobre o manejo florestal só veio a ocorrer com a publicação do Decreto Federal n 1282/1994, que definiu o que seria o manejo florestal sustentável e estabeleceu os seus princípios e diretrizes (BRASIL, 1994). A partir de então houve diversas regulamentações que revogaram este primeiro decreto e apresentaram novas diretrizes para controlar e orientar o manejo florestal na Amazônia Brasileira (BRASIL, 1995; BRASIL, 1998; BRASIL, 2002; BRASIL 2007; BRASIL, 2009).

Durante a CNUMAD, foi consolidada a Agenda 21, na qual, ao tratar do combate ao deflorestamento, foram propostas ações no sentido de ampliar as atividades relacionadas ao manejo, conservação e desenvolvimento sustentável das florestas (CNUMAD, 1992). A preocupação internacional com os altos índices de desmatamento já vinha sendo manifestada. Em 1990, com objetivo de diminuir as taxas de desmatamento no Brasil, havia sido estruturado o Programa Piloto para a Proteção das Florestas Tropicais do Brasil (PPG-7), apoiado pelos países membros do G7, da União Europeia e dos Países Baixos (ANTONI, 2010). Entretanto, somente em 1999, dentro do PPG-7, teve início o projeto "Apoio ao Manejo Florestal Sustentável na Amazônia” (ProManejo), que apoiou 46 projetos como iniciativas promissoras, sendo 14 projetos de manejo florestal comunitário. (IBAMA, 2007).

A utilização dos recursos florestais por comunidades locais para suprir necessidades físicas, econômicas ou culturais, sempre ocorreu de forma espontânea na relação do ser humano com a floresta, no entanto, nas últimas décadas vem desenvolvendo-se um novo conceito de manejo florestal comunitário. A diversidade de contextos, de atores, de objetivos e de tipos de estratégias geram dificuldades para encontrar uma definição que possa englobar a amplitude de experiências e casos de manejo florestal comunitário (AMARAL; AMARAL NETO, 2005). O Programa Federal de Manejo Florestal Comunitário e Familiar definiu o manejo florestal comunitário e familiar como "a execução de planos de manejo realizada pelos agricultores familiares, assentados da reforma agrária e pelos povos e comunidades tradicionais para obtenção de benefícios econômicos, sociais e ambientais, respeitando-se os mecanismos de sustentação do ecossistema”. (BRASIL, 2009).

Para Sunderlin (2006), o sistema em que o manejo florestal é apresentado por agentes externos à comunidade como o governo, agências internacionais ou ONGs locais, ou alguma combinação destes três, é considerado como um "modelo introduzido" de manejo florestal. Neste trabalho, ao ser referido o manejo florestal comunitário, está-se referindo a um "modelo introduzido", pois os projetos de Manejo Florestal Comunitário e Familiar que vêm sendo desenvolvidos no Brasil são decorrentes da presença de ONGs e/ou agências governamentais que visam à melhoria de renda dentro das comunidades e ao atendimento às normas ambientais (STONE-JOVICICH et al., 2007; POKORNY; JOHSON, 2008; MEDINA; POKORNY, 2011; HUMPHRIES et al., 2012).

As dimensões territoriais com possibilidades para o Manejo Florestal Comunitário e Familiar são expressivas. Aproximadamente $44 \%$ da área territorial da Amazônia Legal são formados por Áreas Protegidas, sendo destes, $49 \%$ compostos por Terras Indígenas e 33\% por Unidades de Conservação de Uso Sustentável (PEREIRA et al, 2010). Supondo que fossem implementados planos de manejo florestais em 50\% das Unidades de Conservação criadas até 2004, ter-se-ia uma produção anual de 5,6 milhões de $\mathrm{m}^{3}$, o que corresponderia a $20 \%$ do total dos 28 milhões de $\mathrm{m}^{3}$ produzidos anualmente na Amazônia, na época do estudo (AMARAL; AMARAL NETO, 2005).

Não obstante a esse potencial, a implementação de planos de manejo florestal comunitário e familiar passam, na prática, por grandes dificuldades. Foram identificadas em 2009-2010, 1.213 iniciativas desse tipo de manejo, em seis estados da Amazônia brasileira, sendo a maioria destes, 898, no estado do Amazonas (BRASIL, 2011). Para, Kibler e Silva (2008), muitos desses planos de manejo elaborados no estado do Amazonas, não receberam a licença ambiental de operação que autoriza a exploração, provavelmente devido à centralização do Instituto de Proteção Ambiental do Amazonas (IPAAM) em Manaus, à falta de recursos humanos preparados e às interpretações divergentes das normas. 
As políticas públicas e os marcos regulatórios vêm sendo decisórios no estabelecimento das diretrizes dos projetos de manejo florestal sustentável. Neste trabalho foi realizada uma revisão das normas federais e do estado do Amazonas, para o manejo florestal sustentável, com enfoque no manejo comunitário e no de pequena escala. O objetivo é apresentar e discutir como os instrumentos de regulamentação e de promoção do manejo florestal sustentável na Amazônia brasileira, influenciaram na formação de novos sistemas produtivos dentro do extrativismo madeireiro familiar e comunitário. Será apresentado um estudo de caso desenvolvido na região do baixo Amazonas, no município de Boa Vista do Ramos - AM.

\section{Metodologia}

O estudo foi desenvolvido no estado do Amazonas, município de Boa Vista do Ramos (BVR), a $367 \mathrm{~km}$ via fluvial de Manaus, em uma região denominada de Baixo Amazonas, às margens do Paraná do Ramos, nas bacias dos rios Massauarí e Curuçá (Figura 1).

\section{Figura 1 - Localização do município de Boa Vista do Ramos - Amazonas, e a sede da Associação Comunitária Agrícola e de Extração de Produtos da Florestal.}

Figure 1 - Location of Boa Vista do Ramos - Amazonas state, and Community Agricultural e and Forest Extractive Product headquarters.

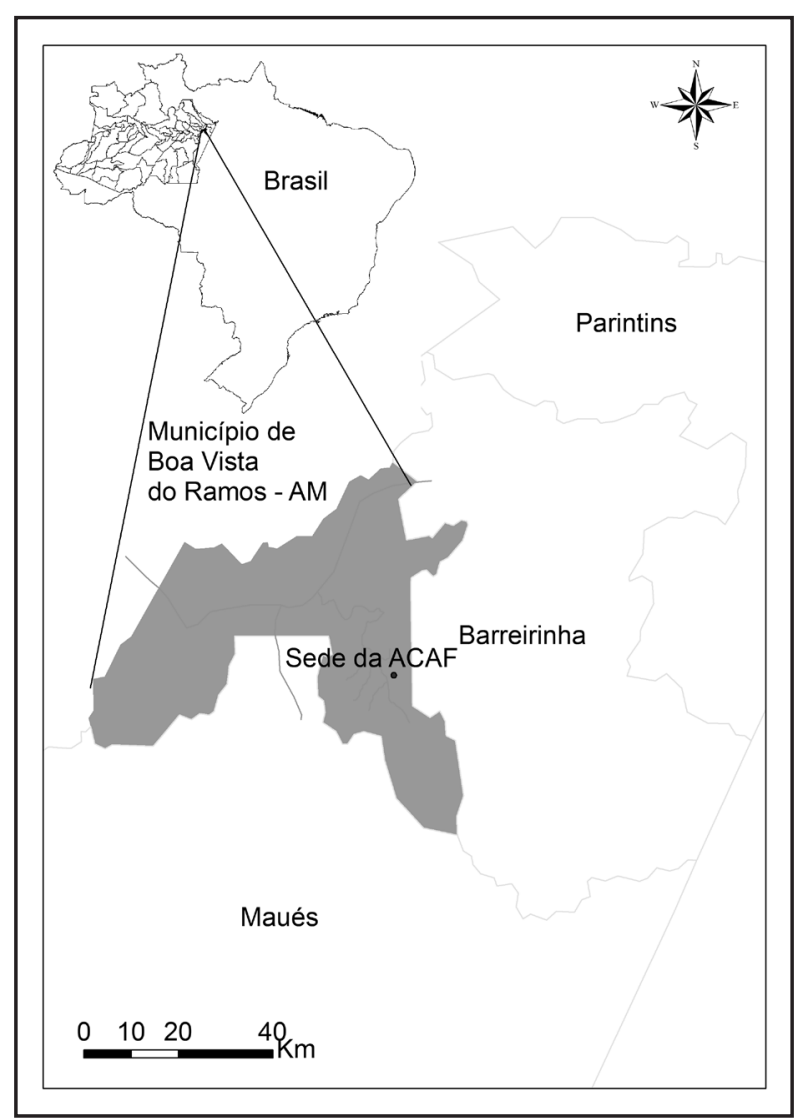

Fonte: Waldhoff e Vidal (2012)

O local onde foi desenvolvido o Plano de Manejo Florestal foi caracterizado como de terra firme formada por latossolos amarelos, com manchas de podzólicos, textura média, ocorrendo solos arenosos e a topografia variando entre plana e suave ondulada. A vegetação do local é de Floresta Ombrófila Densa. As principais espécies de madeiras comerciais encontradas são: Manilkara huberi (Ducke) Cheval (maçaranduba); Dinizia excelsa Ducke (angelim); Mezilaurus itaúba (Meisn.) Taub. 
Ex Mez (itaúba); Tabebuia serratifolia (Vahl) Nich. (ipê-amarelo); Hymenaea courbaril L. (jatobá) e; Minquartia guianensis Aubl. (acariquara), além de diversas espécies de Ocotea sp (louro), Sclerolobium sp (tachi), Astronium sp (muiracatiara) e Couratari sp. (tauari). Os produtos não madeireiros mais comuns são: Bertholletia excelsa H.B.K. (castanha-do-Brasil), Carapa guianensis Aubl. (andiroba), Copaifera sp. (copaíba), Protium sp (breu) e Heteropsis sp (cipó). O único meio de acesso à área é via fluvial.

O estudo foi realizado seguindo as etapas: (i) análise das normas e políticas voltadas ao manejo florestal comunitário; (ii) estudo de caso de uma associação comunitária e; (iii) análise de documentos formais apresentados pela associação.

Visando a uma melhor compreensão do ambiente legal no qual foi desenvolvido o projeto, foi realizada uma revisão das políticas e do arcabouço normativo, voltados ao manejo florestal sustentável comunitário e as Instruções Normativas específicas que serviram de base para elaboração do plano de manejo.

A análise da mudança no arranjo produtivo e na forma de manejo dos produtos florestais madeireiros deu-se com base em um estudo de caso (LUDCKE; ANDRÉ, 1986). Foi estudado o processo de formação e estruturação do manejo florestal comunitário desenvolvido pela Associação Comunitária Agrícola e de Extração de Produtos Florestais (Acaf). O estudo foi desenvolvido com base no método de observação participante e de entrevistas não estruturadas (BERNARD, 1988). As viagens para as comunidades iniciaram em 1999, ano de formação da Acaf, e continuaram constantes até 2007. Durante esse período, foi mantido o diálogo com os presidentes da associação, com diferentes associados e houve a participação direta em reuniões técnicas e assembleias. Foram monitorados em profundidade os trabalhos de: (i) elaboração e implementação do plano de manejo; (ii) processo de certificação florestal - Forest Stewardship Coucil (da sigla em inglês FSC traduzido como Conselho de Manejo Florestal, uma organização não governamental, independente, sem fins lucrativos, criada para promover o manejo responsável das florestas do mundo que, para isso, elaboraram-se padrões capazes de avaliar se os empreendimentos florestais realizam o bom manejo florestal) e o atendimento às condicionantes; e (iii) implementação do projeto "Manejo florestal por meio do planejamento participativo nas comunidades do rio Curuçá - Boa Vista do Ramos - AM", apoiado pelo ProManejo/PPG7.

A análise documental foi focada na documentação apresentada pela associação no processo de formalização, regularização fundiária, licenciamento ambiental e certificação florestal (Tabela 1).

Tabela 1 - Documentos relativos à Associação Comunitária Agrícola e de Extração de Produtos da Floresta incluídos na análise documental.

Table 1 - Documents related to the Community Association of Agricultural and Forest Products included in documentary analysis.

\begin{tabular}{l|c}
\hline $\mathbf{N .}$ & Documento \\
\hline $\mathbf{1}$ & Atas de reuniões da associação \\
$\mathbf{2}$ & Regimento interno \\
$\mathbf{3}$ & Estatuto social \\
$\mathbf{4}$ & Cadastro nacional de pessoa jurídica \\
$\mathbf{5}$ & Plano de Manejo Florestal Sustentável \\
$\mathbf{6}$ & Alanos Operacionais Anuais das Unidades Produtivas \\
$\mathbf{7}$ & Declarações de venda de produtos florestais \\
$\mathbf{8}$ & Relatórios de certificação florestal \\
$\mathbf{9}$ & Relatórios do projeto do ProManejo-PPG7 \\
$\mathbf{1 0}$ &
\end{tabular}

Fonte: Waldhoff e Vidal (2012) 


\section{Resultados e discussão}

Inicialmente será apresentado o contexto legal e normativo vigente no período em que se desenvolveu o projeto. A seguir, o histórico de criação da Acaf. E, por fim, apresentar-se-ão os resultados do projeto de manejo florestal comunitário da Acaf separados nos temas: (i) trocas de experiências e treinamentos; (ii) regularização fundiária, legalização e certificação florestal; (iii) plano de manejo florestal; (iv) capacidade de influenciar e irradiar o manejo para outras iniciativas na região.

\section{Normas para o manejo florestal com enfoque nos aspectos comunitários e de pequena escala}

As regulamentações para o manejo florestal sustentável tiveram início em 1994, mas foi o Decreto Federal $n^{\circ} 2.788 / 1998$, que possibilitou a apresentação de plano de manejo florestal simplificado (BRASIL, 1998). O referido decreto deu margem para que pequenos produtores florestais, agroextrativistas e agricultores familiares, desenvolvessem, em glebas rurais de até 500 hectares, planos de manejo simplificados (com menos requisitos técnicos). Possibilitou também, que as explorações florestais efetuadas de forma comunitária, por intermédio de associações ou cooperativas, fossem realizadas mediante a apresentação de um único plano de manejo florestal sustentável simplificado. O plano de manejo deveria respeitar o limite de 500 ha anualmente explorados. Foi esse decreto e as Instruções Normativas dele decorrentes que impulsionaram os principais projetos de manejo comunitários desenvolvidos no final dos anos 90 e início da primeira década de 2000, na Amazônia brasileira.

Em 2002, o Ministério do Meio Ambiente (MMA) passou a regulamentar o manejo florestal e editou a Instrução Normativa (IN) Federal $n^{\circ} 4$. Essa IN trouxe problemas para a regulamentação de planos de manejo comunitários, pois estabeleceu o limite máximo de 500 ha para área total do plano de manejo florestal e não mais como limite de área a ser anualmente explorada. No entanto, as áreas comunitárias normalmente apresentavam dimensões superiores a 500 ha. Nesse caso, os planos de manejo passaram a ser classificados como manejo florestal empresarial. Essa classificação implicou a adoção de procedimentos técnicos e administrativos mais sofisticados, nem sempre acessíveis aos projetos comunitários.

Em 2006, a Lei Federal no 11.284/2006 (Lei de Gestão de Florestas Públicas) e o Decreto Federal $\mathrm{n}^{\circ} 5.975 / 2006$ promoveram a descentralização da gestão ambiental, passando o licenciamento dos planos de manejo florestais a ser realizado pelos órgãos estaduais de meio ambiente (OEMAs). Mesmo assim, o Ministério do Meio Ambiente editou novas Instruções Normativas Federais, a IN 4/2006, que dispõe sobre a Autorização Prévia à Análise Técnica e a IN 5/2006, que dispõe sobre os procedimentos técnicos de Plano de Manejo Florestal Sustentável (BRASIL, 2007). As novas instruções não estabeleceram diretrizes específicas para o manejo florestal simplificado e o comunitário, não reconhecendo as peculiaridades dos diferentes grupos sociais. Por outro lado, essas instruções inovaram ao separar a análise da viabilidade jurídica do projeto (IN 4/2006), da análise da viabilidade técnica do plano de manejo (IN 5/2006). Outra inovação importante foi a de estabelecer procedimentos diferenciados para os planos de manejo, em função da intensidade de exploração. Foram criadas duas categorias de plano de manejo florestal: o pleno e o de baixa intensidade.

A descentralização da gestão florestal gerou a princípio certa disputa sobre as competências e os papéis dos órgãos federais e os estaduais. Visando diminuir os conflitos, o Conselho Nacional do Meio Ambiente (CONAMA) publicou a Resolução Federal n 406/2009 (BRASIL, 2009), ressaltando a obrigatoriedade de sua aplicação em qualquer nível de competência pelos órgãos integrantes do Sistema Nacional do Meio Ambiente - SISNAMA. No entanto, nenhum destes instrumentos legais abordou novamente a questão do manejo florestal comunitário, que só veio a ser mencionado novamente com a Lei Federal n 12.651/2012 (novo Código Florestal) no 
qual foi previsto o estabelecimento de disposições diferenciadas (BRASIL, 2012).

Ainda, sob a ótica da descentralização, o Estado do Amazonas, em particular, já vinha assumindo a gestão florestal desde 2003, quando foi criada a Secretaria de Estado do Meio Ambiente e Desenvolvimento Sustentável (SDS). A SDS promoveu o desenvolvimento de projetos de manejo florestal em pequena escala e estabeleceu um convênio com o IBAMA para que Instituto de Proteção Ambiental do Amazonas assumisse a responsabilidade sobre o licenciamento ambiental de Planos de Manejo Florestal Sustentáveis de Pequena Escala. Para dar as diretrizes aos órgãos estaduais, a SDS publicou, em 2003, a Portaria Estadual $\mathrm{n}^{\circ} 40 / 03$, estabelecendo procedimentos orientadores para a apresentação, tramitação, acompanhamento e condução das atividades de PMFSPE (KIBLER; SILVA, 2008). Essa Portaria estabeleceu, entre outros aspectos, o tamanho máximo 500 hectares para o desenvolvimento dos projetos e o limite máximo de $1 \mathrm{~m}^{3} /$ ha a ser anualmente explorado, sem a necessidade da subdivisão da área em talhões anuais. Em 2011, o Conselho Estadual de Meio Ambiente do Estado do Amazonas aprovou a Resolução Estadual $\mathrm{N}^{\circ}$ 007/2011, consolidando a política estadual do manejo florestal em pequena escala. A resolução reduziu a intensidade de exploração para $0,86 \mathrm{~m}^{3} / \mathrm{ha}$, seguindo as normativas federais. Também, adotou medidas inclusivas quando possibilitou aos ocupantes de terras públicas estaduais, de até 4 módulos fiscais e sem o documento de posse, de apresentar o PMFSPE (AMAZONAS, 2011).

\section{Contextualização da formação da ACAF}

Os moradores das comunidades da região dos rios Massauarí e Curuçá, no município de Boa Vista do Ramos, já tinham tradição na extração de madeira muito antes de o ambiente político e normativo, apresentava-se favorável ao desenvolvimento de projetos de manejo florestal comunitário, em 1998. Em um mapeamento participativo realizado no município, em 1999, foram identificados 250 entrevistados com vínculo com exploração madeireira, dos quais 139 possuíam motosserra (KOURY, 2007).

Segundo o Sr. Francisco Valente, primeiro presidente da Acaf (informação verbal), o trabalho era realizado dentro de um sistema de extração seletiva de espécies de interesse comercial. Realizada por pequenos grupos de caráter familiar, a extração de madeira atendia a encomendas específicas principalmente para a construção de casas e mobiliário em geral. O desdobro das árvores derrubadas era realizado com a motosserra, dentro da própria floresta, de acordo com as dimensões, volumes e espécies solicitadas. A madeira era transportada manualmente de dentro da floresta até à margem de algum igarapé ou rio, em seguida, por meio de barcos, até algum entreposto ou consumidor. Os principais mercados encontravam-se no próprio município ou nos municípios vizinhos de Maués e de Parintins. A tradição de extração de madeira na região vem de antes mesmo do uso da motosserra, quando os trabalhos eram feitos com o machado. O trabalho era desenvolvido dentro do contexto de uso dos recursos naturais adaptado às condições das comunidades locais, realizado com base no conhecimento tradicional das espécies e do sistema de extração.

A mudança para o "modelo introduzido" de manejo florestal teve origem com a chegada ao município do Instituto de Manejo e Certificação Florestal e Agrícola (Imaflora - organização brasileira, sem fins lucrativos que verifica a adequação dos empreendimentos florestais conforme os critérios do FSC). O Imaflora iniciou em 1998, em parceria com a Prefeitura Municipal de Boa Vista do Ramos, um projeto de mapeamento participativo do potencial agroextrativista do município (IMAFLORA, 2002). Nesta época, a cadeia produtiva da madeira funcionava com base na informalidade e na ilegalidade, pois seriam necessários minimamente para extração e comercialização de madeira a Licença de Operação (LO), a Autorização de Exploração (AUTEX) e o Documento de Origem Florestal (DOF), além das notas fiscais. No entanto, alguns extratores de madeira na região do Curuçá, influenciados pela Associação de Pequenos Extratores de Madeira de Parintins, já mostravam interesse em formarem uma associação e buscarem o caminho para 
a regularização das atividades.

Os extratores de madeira se organizaram e formaram a Acaf em 1999, o que levou ao fortalecimento de relações institucionais com o Imaflora, com a Prefeitura Municipal de BVR e com o Instituto Federal de Educação, Ciência e Tecnologia do Amazonas - IFAM, campus zona leste (ex-Escola Agrotécnica Federal de Manaus - EAFM). A assistência técnica ofertada pelo Imaflora e pelo IFAM, entre 1999 e 2007, foi mais intensa que os padrões habituais, envolvendose integralmente na elaboração do plano de manejo, apoiando a formação da associação e o desenvolvimento institucional. O arranjo institucional entre a Acaf e os parceiros, possibilitou a estruturação do projeto de manejo florestal sustentável comunitário que viria a se tornar uma referência para manejo florestal comunitário na região do baixo Amazonas. O projeto elaborado foi fruto da interação entre o conhecimento técnico/científico e o conhecimento tradicional.

\section{Resultados do projeto de manejo florestal comunitário da ACAF}

\section{Trocas de experiências e treinamentos}

Para que pudesse ser estruturado um Plano de Manejo Florestal Sustentável foi necessário estabelecer uma relação de confiança entre as instituições e as pessoas envolvidas no processo. Essa confiança foi alcançada durante os treinamentos, prévios à elaboração do Plano, que permitiram um amadurecimento das relações pessoais e institucionais.

A primeira atividade desenvolvida conjuntamente pelas quatro instituições envolvidas no projeto foi o inventário florestal amostral na região do Curuçá em maio de 1999. O trabalho foi realizado aliando o conhecimento tradicional a respeito da floresta e das espécies florestais, com o conhecimento técnico-científico de amostragem e inventário florestal. Depois, foi aplicado um curso de uso e manutenção de motosserras e de técnicas de corte de árvores, aplicado pelo Instituto Floresta Tropical - IFT. O resultado foi positivo, pois, ao se agregar o conhecimento dos especialistas à experiência dos comunitários no manuseio de motosserras, obteve-se um avanço qualitativo nos aspectos ambientais e econômicos, pois tais técnicas diminuem os danos na floresta remanescente e os desperdícios de madeira (AMARAL et al, 1998). A partir de então, houve um período, entre 2000 e 2007, de intenso intercâmbio com os alunos e professores do Curso Técnico em Manejo Florestal do IFAM. A experiência e o saber dos comunitários e o conhecimento dos técnicos do Imaflora e do IFAM foram compartilhados mutuamente, estabelecendo-se um verdadeiro laboratório no aprendizado do manejo florestal comunitário.

O financiamento, com recursos não reembolsáveis, do projeto: "Manejo florestal por meio do planejamento participativo nas comunidades do rio Curuçá - Boa Vista do Ramos/AM", pelo Projeto de Apoio ao Manejo Florestal Sustentável na Amazônia (ProManejo/PPG7), em 2004, permitiu um salto qualitativo no trabalho da Acaf. O projeto teve duração de 27 meses e possibilitou a realização de diversos intercâmbios e treinamentos (Tabela 2).

A riqueza de experiências vivências pelos associados possibilitou o fortalecimento do capital humano da Acaf. Ao receberem qualificação em manejo florestal, muitos dos associados passaram a ser requisitados para outros projetos de manejo florestal na região, desempenhando atividades específicas. Neste sentido, pode-se identificar um dos princípios do conceito de desenvolvimento territorial (PECQUEUR, 2005), cujo diferencial adquirido por aqueles que participaram dos treinamentos e intercâmbios, passa a ser valorizado, beneficiando empreendimentos que se instalam na região. No entanto, o fortalecimento em relaçãoà organização social e à capacidade técnica na área de manejo florestal (KOURY, 2007), não foi devidamente acompanhado de estratégias para promover o empoderamento (OAKLEY; CLAYTON, 2003) e a potência de ação (ALVES et al., 2010) da Acaf, podendo ser um dos fatores que levou à paralisação das atividades em sua área, a partir de 2008. 


\section{Tabela 2 - Principais cursos e intercâmbio realizados pelos associados da Associação Comunitária Agrícola e de Extração de Produtos da Floresta.}

Table 2 - Main courses and interchanges carried out by Community Association of Agricultural and Forest Products Harvesting.

\begin{tabular}{l|r}
\hline \multicolumn{1}{c|}{$\mathbf{N}}$. & Atividade \\
\hline $\mathbf{1}$ & Curso sobre forma de representação jurídica: associativismo, cooperativismo, etc. \\
$\mathbf{2}$ & Curso de administração e contabilidade aplicada ao terceiro setor \\
$\mathbf{3}$ & Intercâmbio com outra iniciativa de manejo florestal comunitário em Xapuri-AC \\
$\mathbf{4}$ & Intercâmbio com a empresa certifica Mil Madeireira em Itacoatira-AM \\
$\mathbf{5}$ & Curso sobre noções básicas em segurança do trabalho e prevenção de acidentes \\
$\mathbf{6}$ & Curso sobre classificação de madeiras, entre outros \\
\hline
\end{tabular}

Fonte: Waldhoff e Vidal (2012)

\section{Regularização fundiária, legalização e certificação das atividades florestais}

\section{Regularização fundiária}

Para iniciar um projeto de manejo florestal é imprescindível ter o direito legal de acesso a uma área florestal a qual será manejada. Para a Acaf, esta etapa poderia ter se tornado intransponível caso não houvesse na época uma política pública favorável ao manejo florestal comunitário. Neste contexto, foi realizada na Comunidade Menino Deus do Curuçá a 3ª Oficina de Manejo Florestal Comunitário, em 2000, promovida pelo ProManejo com apoio do Instituto Internacional de Educação do Brasil (IEB - organização civil, sem fins lucrativos, voltada para a capacitação e formação de pessoas ligadas à conservação ambiental). Durante essa oficina, foi definida entre os comunitários, autoridades e lideranças presentes, uma área para o desenvolvimento das atividades da Acaf. A área foi cedida pela Prefeitura Municipal de Boa Vista do Ramos, por meio de uma concessão de direito real de uso, documento que permitiu o início da elaboração do Plano de Manejo Florestal e a solicitação das licenças ambientais aos órgãos competentes.

A concessão expedida pela prefeitura possibilitou o desenvolvimento das atividades relacionadas às Unidades de Produção Anual (UPA) 1 e 2, mas, como verificada posteriormente, a área em questão era de jurisdição do estado, e a concessão passou a não ter mais validade legal. Desta forma, foi solicitada junto ao Instituto de Terras do Estado do Amazonas, em julho de 2004, a regularização da área. No entanto, surgiram 2 problemas de ordem jurídica: (i) áreas acima de 1500 ha, teriam de ser aprovadas pela Assembleia Legislativa do Estado do Amazonas, para ser titulada e (ii) não existem mecanismos na Lei Estadual de Terras para titulação de áreas coletivas. Para contornar os problemas, de forma paliativa, em novembro de 2004, o Instituto de Terras do Estado do Amazonas emitiu 3 Cartas de Anuência em nome de associados da Acaf, desmembrando a área de 2400 ha, em três áreas menores.

Após a perda de validade das Cartas de Anuência, foram solicitados três Títulos Definitivos do Instituto de Terras do Estado do Amazonas, em nome de associados da Acaf, seguindo as mesmas orientações para a solicitação das Cartas de Anuência. A celeuma da questão fundiária permaneceu sem os devidos encaminhamentos até 2012, sendo o principal entrave para a continuidade das atividades da Acaf na área de manejo florestal. Fica evidente a dificuldade institucional e jurídica de se trabalhar com projetos de manejo florestal comunitário, principalmente daqueles fora de unidades de conservação ou assentamentos oficiais, em que, 
muitas vezes, os documentos fundiários, quando existem, não apresentam respaldo jurídico (HAJJAR et al., 2011).

\section{Legalização e certificação}

O plano de manejo florestal sustentável da Acaf seguiu as prerrogativas do Decreto Federal 2.788/1988 e as orientações da Instrução Normativa Federal do IBAMA № 4/1998, para a exploração de recursos florestais na bacia amazônica de forma comunitária. Foi dada a entrada do Plano de Manejo Florestal Sustentável Comunitário e do Plano Operacional Anual (POA-1) junto ao IBAMA e ao Instituto de Proteção Ambiental do Amazonas (IPAAM), em abril de 2001. A Licença de Operação (LO) e a Autorização de Exploração (AUTEX), foram emitidas em julho e agosto do mesmo ano (Tabela 3). Com as licenças vigentes foram desenvolvidas as atividades de exploração florestal e elaborado um novo Plano Operacional Anual (POA-2).

Foi dada entrada para a solicitação de licenças para a UPA 2 em agosto de 2002. Neste período, a publicação da IN Federal no 4/2002, do Ministério do Meio Ambiente, vinha causando dificuldades para os projetos de manejo florestal comunitários que estavam sendo desenvolvidos (IBAMA, 2009). No caso da ACAF, como a área total da propriedade era superior a 500 hectares, deveriam ser seguidas as prerrogativas de Plano de Manejo Florestal Sustentável de Uso Múltiplo em Escala Empresarial (BRASIL, 2002). Na prática, isto significaria que a ACAF, que explorava aproximadamente de 50 ha por ano, deveria apresentar um projeto com os mesmos detalhes de um projeto empresarial que explorasse centenas ou milhares de hectares anualmente. Após muitas negociações a LO e a AUTEX foram emitidas em dezembro de 2003 e janeiro de 2004. Este longo tempo de espera para as novas licenças levou ao descontentamento e desmotivação de muitos dos associados e foi um dos grandes entraves vivenciados pela Acaf no decorrer de suas atividades.

Vencidas as dificuldades, as atividades de manejo foram desenvolvidas normalmente e, em 2005, foi solicitada uma nova AUTEX para o IBAMA, emitida em outubro do mesmo ano. A LO, solicitada em dezembro de 2005 ao IPAAM, só foi concedida mais de 8 meses depois. A demora foi atribuída à descentralização da gestão florestal, que determinou a transferência do plano de manejo do IBAMA para o Instituto de Proteção Ambiental do Amazonas que ficou responsável também pela análise do plano de manejo.

Durante o período em que Acaf desenvolveu atividades florestais em sua área - entre 1998 e 2006 - identificou-se a alteração das Instruções Normativas para manejo florestal sustentável por três vezes, em 2001, 2002 e 2006. Fialho (2009) destaca a necessidade de simplificação do processo burocrático, para promover a expansão da base produtiva florestal no Estado do Paraná, no entanto, esta necessidade se faz presente também para a expansão do manejo florestal comunitário na Amazônia brasileira. As mudanças nas normas de manejo promoveram um aumento da complexidade nos procedimentos burocráticos para o manejo comunitário, gerando incertezas sobre novas normas de conduta do manejo e insegurança para o setor produtivo.

Mesmo diante a este cenário de mudanças normativas e de burocracia, os associados da Acaf tiveram a oportunidade de aprimorar-se tecnicamente e a associação tornou-se uma referência social e ambiental para as comunidades do baixo Amazonas. Surgiu a oportunidade de iniciar, em 2004, o processo de certificação florestal do Forest Stewardship Council (FSC), realizado pela Scientific Certification Systems, uma empresa internacional credenciada para certificar pelo FSC. A auditoria de certificação foi feita em maio de 2004. Foram emitidas 17 precondicionantes (a serem cumpridas antes da certificação) e 10 condicionantes (a serem cumpridas após a certificação). Em fevereiro de 2005, a associação adquiriu a Certificação Florestal do FSC, o mais importante e reconhecido selo socioambiental do setor florestal. Os custos diretos da primeira auditoria de certificação foram cobertos pelo WWF-Brasil. 


\section{Tabela 3 - Datas e períodos das principais ações de regularização da Associação Comunitária Agrícola e de Extração de Produtos da Floresta.}

Table 3 - Main actions dates and periods of Community Association of Agricultural and Forest Products Harvesting regularization.

\begin{tabular}{|c|c|c|c|}
\hline No. & Ação & Data & Período (entre ações) \\
\hline 1 & Fundação ACAF & 06/ago/99 & \\
\hline 2 & Solicitação de LO e AUTEX - UPA 1 & 09/abr/01 & 1 e $2: 20$ meses e 12 dias \\
\hline 3 & Vistoria IPAAM & 10/mai/01 & 2 e 3: 01 mês e 01 dia \\
\hline 4 & Liberação LO - UPA 1 - IPAAM & 23/jul/01 & 2 e $4: 03$ meses e 15 dias \\
\hline 5 & Liberação AUTEX - UPA 1 - IBAMA & 10/ago/01 & $\begin{array}{l}2 \text { e 5: } 04 \text { meses e } 10 \text { dias } \\
1 \text { e 5: } 24 \text { meses e } 04 \text { dias }\end{array}$ \\
\hline 6 & Solicitação de LO e AUTEX - UPA 2 & 07/ago/02 & \\
\hline 7 & Liberação LO - UPA 2 - IPAAM & 05/dez/03 & 6 e $7: 16$ meses e 5 dias \\
\hline 8 & Liberação AUTEX UPA 2 - IBAMA & $\mathrm{jan} / 04$ & 6 e $8: 17$ meses e 2 dias \\
\hline 9 & ITEAM - Solicitação de Reg. Fundiária & 07/jul/04 & \\
\hline 10 & $\begin{array}{c}\text { ITEAM - Solicitação de Reg. Fundiária - } \\
\text { reentrada }\end{array}$ & $24 /$ set $/ 04$ & \\
\hline 11 & ITEAM - Carta de Anuência p / ACAF & 08/nov/04 & 9 e 11: 04 meses e 13 dias \\
\hline 12 & Certificação FSC: SCS FM-COC-00082N & $\mathrm{fev} / 05$ & 1 e $12: 66$ meses e 26 dias \\
\hline 13 & Liberação UPA 3 - IBAMA (AUTEX) & 06/out/05 & \\
\hline 14 & Solicitação a IPAAM de L.O. para UPA-3 & 15/dez/05 & \\
\hline 15 & Solicitação de Transferência IBAMA - IPAAM & $20 / \mathrm{mar} / 06$ & \\
\hline 16 & Liberação UPA 3 - IPAAM (LO) & 29/ago/06 & 14 e 16: 08 meses e 17 dias \\
\hline
\end{tabular}

Fonte: Koury (2007)

O processo de certificação foi de grande importância para a melhoria dos processos internos da associação principalmente no que se refere a aspectos sociais e ambientais. No entanto, devido às grandes distâncias para os centros consumidores de madeira certificada e ao mesmo tempo, os baixos volumes produzidos, os benefícios econômicos com a venda da madeira certificada, não foram muito expressivos. Devidos aos custos da certificação e à impossibilidade legal de continuar o manejo florestal (pela documentação fundiária), em 2008 a Acaf perdeu o selo do FSC.

\section{Plano de Manejo Florestal}

O plano de manejo florestal da Acaf foi desenvolvido em uma área de 2400 hectares, destinadas exclusivamente para o manejo florestal, na Comunidade Monte Horebe, região do rio Curuçá, Município de Boa Vista do Ramos - AM. O plano previu um ciclo de 25 anos em sistema policíclico com unidades de produção anual (UPA) de até 80 ha. Nas UPA exploradas foram realizados o inventário de todas as espécies comerciais e potencialmente comerciais com o Diâmetro Acima do Peito acima de $45 \mathrm{~cm}$ e confeccionado o mapa de exploração florestal. Foi 
realizado o corte de cipós junto às árvores que seriam exploradas. O sistema de colheita florestal era manual, sendo as árvores derrubadas com motosserras utilizando-se técnicas de derrubada direcionada. As toras eram desdobradas no local, utilizando-se, no início do projeto, a motosserra e, depois, passou-se a utilizar uma serraria portátil. O transporte primário, considerado aqui como o transporte até as margens de um curso d'água que permita navegação de barcos regionais, era feito de forma manual, depois, com o apoio de um microtrator agrícola com reboque. $\mathrm{O}$ transporte secundário, da margem dos igarapés até os pontos de consumo e/ou comercialização, era feito por via fluvial em embarcações regionais de pequeno calado.

O manejo florestal da Acaf sempre foi plenamente coletivo, sendo que, não houve a subdivisão da área de manejo em lotes para trabalhos individuais ou de subgrupos. Todas as tarefas foram planejadas e desenvolvidas conjuntamente. Formaram-se equipes de trabalho para determinadas tarefas do manejo florestal de acordo com as habilidades individuais específicas. Associados que melhor identificavam as árvores trabalhavam nesta função durante o inventário florestal, Da mesma forma, os que tinham maiores habilidades no manuseio da motosserra, eram responsáveis pela derrubada direcionada das árvores. O monitoramento, o controle do trabalho, os valores e a quantidade de diárias a serem pagos eram feitos pelos próprios associados. As atividades de exploração eram realizadas somente com o fechamento do contrato de comercialização. Pagos todos os valores de diárias e outros custos operacionais, o lucro da operação era em parte aplicado na própria associação.

Foram manejadas três UPA entre 2001 a 2007. As duas primeiras UPA foram de 50 ha e a terceira de 80 ha. A produção florestal sempre foi menor do que $20 \%$ do potencial madeireiro autorizado. No caso da UPA 2, em que foi autorizada uma exploração de $1900 \mathrm{~m}^{3}$ de madeira em pé, só foram comercializados $103,33 \mathrm{~m}^{3}$ de madeira serrada. A causa principal foi o atraso da liberação das licenças e dificuldades de conseguir compradores de pequenos volumes de madeira certificada. Para Koury (2007), o projeto da ACAF foi considerado economicamente insustentável. Sendo a depreciação das máquinas e equipamentos principal responsável pelo alto custo de produção, em relação ao baixo volume comercializado. O autor apontou para a necessidade de buscar alternativas para melhorar a gestão do projeto e para atingir a maturidade do empreendimento florestal comunitário, que estabeleçam um melhor arranjo produtivo e diminuam os custos mencionados.

Um caminho para a diminuição dos custos seria aumentar o número de operações em campo, ou seja, a produção, o que diluiria os custos administrativos e os da depreciação. A intensidade de exploração próxima de $2 \mathrm{~m}^{3} /$ ha realizada pela ACAF foi bastante baixa. Carvalho e Oliveira (2010), estudando a viabilidade econômica do manejo florestal madeireiro em áreas extrativistas na Amazônia, encontrou um valor presente líquido positivo apenas para intensidade de $9,8 \mathrm{~m}^{3} /$ ha. Em contraponto às avaliações muito focadas nos aspectos econômicos, Wanderley (1989) considerou que em unidades de produção familiar, como pode ser considerado o modelo de manejo da Acaf, os princípios que regem o funcionamento interno são diferentes daqueles encontrados na unidade de produção capitalista, pois são os próprios proprietários são a fonte de trabalho que aciona o capital envolvido no processo de produção. No final do processo, é o produtor quem efetua um balanço entre o esforço exigido para a realização do trabalho e o grau de satisfação das suas necessidades.

Considerando uma visão ampla sobre a Amazônia, Angelo et al. (2004) apontaram que o manejo florestal sustentável ainda não contribui significativamente para explicar a oferta de madeira tropicais da região. Para Hajjar et al. (2011), a madeira originária de desmatamentos ou da extração ilegal entram com produtos mais baratos no mercado de madeira, sendo um entrave para a viabilidade de projetos de manejo florestal sustentável. 


\section{Capacidade de influenciar e irradiar o manejo para outras iniciativas na região}

O projeto de manejo florestal comunitário da Acaf transformou com relação aos aspectos técnicos, sociais e ambientais, a forma de atuação dos extrativistas florestais na região do baixo Amazonas, principalmente nas calhas dos rios Massauarí e Curuçá. Mas, até alcançar resultados positivos, houve muitos questionamentos e desconfianças por parte dos comunitários da região. No início, o trabalho de mapeamento participativo do município e a aproximação de instituições desconhecidas levaram à especulação de que as terras seriam fornecidas a grupos estrangeiros. Ao mesmo tempo, o processo de legalização das atividades florestais fez com representantes de órgãos ambientais viessem para a região, provocando o desconforto em extratores que permaneceram alheios à legalização. Somado a estes fatores, o longo período de tempo (três anos) necessário à formalização e legalização das atividades, até à extração e comercialização da madeira legalizada, gerou dúvidas a respeito da viabilidade do projeto. Portanto, mesmo sendo uma iniciativa dos moradores locais, a um primeiro momento, a iniciativa não contou com um amplo apoio das comunidades da região.

A credibilidade local do projeto só começou a melhorar com a comercialização das madeiras da UPA 2, em 2004. Logo a seguir, o apoio do ProManejo ao projeto permitiu a estruturação e o fortalecimento da atuação da Acaf. Em 2005, o trabalho foi reconhecido pela sua qualidade técnica, ambiental e social, e recebeu o certificado FSC. Este novo panorama fez com muitos extratores de madeira da região que ainda não tinham manifestado interesse na legalização passassem a se aproximar do projeto e buscar orientações. No período entre 2004 e 2007, a Acaf consolida-se como um projeto de referência para os comunitários do baixo Amazonas que buscavam um caminho para realizar o manejo florestal.

A experiência da Acaf foi importante para estimular muitos dos extratores que vinham trabalhando de forma ilegal a buscarem novas alternativas. Em outubro de 2007, é formada a Associação dos Manejadores Florestais do Curuçá, uma associação cujos projetos de manejo florestal são todos individuais, desenvolvidos dentro do escopo das normas estaduais para o manejo florestal em pequena escala. Alguns dos associados da Acaf também se filiaram à nova associação e procuraram desenvolver planos de pequena escala. De acordo com os estudos voltados aos "dilemas da ação coletiva" (CUNHA, 2004), esta estratégia na busca de adquirir de imediato algum benefício individual condiz com uma situação em que há incertezas nos resultados do trabalho coletivo. Além de terem alguns membros dentro da nova associação, com planos de manejo desenvolvidos individualmente, os associados da Acaf sempre contribuíram com aporte de conhecimento técnico e equipamentos, para a elaboração e a colheita dos projetos de pequena escala.

Três períodos marcaram a história da Acaf. O período inicial, de 1999 a 2002, quando as dificuldades de estruturação e legalização das atividades foram preponderantes. O período de atividades intensas, entre 2003 e 2007, com intercâmbios, treinamentos, apoios institucionais, certificação florestal e comercialização de madeira. E o período de entraves e mudanças, entre 2008 e 2012, quando por motivos de mudanças de políticas, por conflitos entre gestão estadual e federal e pela impossibilidade de regularização fundiária, foram paralisadas as atividades florestais dentro da área da Acaf. Nesse período, a ACAF passou a desempenhar um papel preponderante na disseminação do manejo em toda a região, apoiando as outras associações e ajudando na elaboração de projetos de manejo florestal simplificado.

A capacidade da Acaf de influenciar positivamente o ambiente social a favor do manejo florestal se mostrou como um processo de mobilização dos atores locais, com base na identificação coletiva de uma cultura e um território, se apresentando como uma estratégia de adaptação aos limites externos, o que, para Pecqueur (2005), caracteriza-se como desenvolvimento territorial. Os principais limites externos enfrentados pela Acaf identificados neste projeto foram o aumento da regulamentação florestal e ambiental, pressão social e de órgãos oficiais sobre a madeira 
ilegal e a dificuldade de regularização fundiária para o acesso aos recursos florestais.

\section{Conclusões}

As constantes mudanças nas políticas e programas públicos e nas regulamentações do manejo florestal dificultam muito o caminho na busca da regularização da atividade. O manejo florestal sustentável na Amazônia ainda é um desafio a ser superado. Exemplos de empresas ou comunidades que apresentam sustentabilidade econômica, ambiental e social a partir do manejo florestal madeireiro, são escassos. Neste sentido, a Acaf foi propulsora de mudanças na forma tradicional de uso dos recursos florestais madeireiros em busca da legalização e sustentabilidade do manejo florestal na região do baixo Amazonas.

As políticas públicas para o desenvolvimento do manejo florestal comunitário e familiar devem ser fortalecidas. O Programa Nacional de Manejo Florestal Comunitário e Familiar e o Programa de Manejo Florestal em Pequena Escala no Estado do Amazonas estão aquém das necessidades e do potencial que o setor apresenta. $O$ manejo florestal em pequena escala, desenvolvido no município de Boa Vista do Ramos, com apoio do Estado atuando em toda cadeia produtiva, tem se apresentado mais aplicável ao sistema de produção das comunidades desta região. O empoderamento dos manejadores florestais deve ser entendido como uma ação estratégica a ser contemplada dentro dos programas e projetos visando à superação das dificuldades, à inclusão social e à autonomia do manejo florestal comunitário.

\section{Agradecimentos}

Aos comunitários: Sr. Francisco Valente; Claudio Soares; e Darcy Gonçalves, presidentes da Acaf (1999/2007), e em nome deles aos demais associados e comunitários que contribuíram com o trabalho. Aos engenheiros florestais Maximiliano Roncoletta, Cássio C. Guisti e Marcus A. Biazatti e aos técnicos florestais Gilson Q. Branco e Joel F. da Trindade que trabalharam diretamente com a ACAF. Ao professor Lúcio Rabelo, diretor da IFAM no início do trabalho. Ao educador Adalberto Guerreiro, da Casa Familiar Rural de BVR. Ao Sr. Vasco Ribeiro, ex-prefeito de BVR, que emitiu a concessão de uso para o manejo florestal. Ao professor Marcos Sorrentino e a Carlos G. Koury pelas discussões.

\section{Referências}

AMARAL, P.; NETO, M. A. Manejo florestal comunitário: processo de aprendizagem na Amazônia brasileira e na América Latina. Belém: IEB: IMAZON, 2005. 84p.

AMARAL, P. et al. Floresta para sempre: um manual para a produção de madeira na Amazônia, Belém: Imazon, 1998, 130p. Disponível em: http://www.imazon.org.br/publicacoes/livros/florestapara-sempre-um-manual-para-a-producao-de. Acesso em: 05.10.2011

AMAZONAS, 2011. Resolução Estadual CEMAAM n 07, de 21 de junho de 2011. Estabelece normas e procedimentos para PMFSPE. Disponível em: http://www.idam.am.gov.br/arquivo/ recomendacoes/ cb4e4df966a19974200fd7dcce9d23be.pdf. Acesso em: 06.11.2011

ANGELO, H.; PRADO, A. C.; BRASIL, A. A. Influência do manejo florestal e do desmatamento na oferta de madeiras tropicais na Amazônia brasileira. Ciência Florestal, Santa Maria, v. 14, n. 2, p. 103-109, 2004.

ANTONI, G. de. O Programa Piloto para Proteção das Florestas Tropicais do Brasil (PPG-7) e a globalização da Amazônia. Ambiente e Sociedade, Campinas, v. XIIIi, n.2, p. 299-313, jul-dez 2010. 
BERnARD, H. R. Methods in Cultural Anthropology. Ed. Sage Publications. 1988. Califórnia. 518p. Disponível em: http://pt.scribd.com/rub\%C3\%A9ng_35/d/45081103-Bernard-H-RussellResearch-Methods-in-Cultural-Anthropology. Acesso em: 30.03.2012

BRASIL. Decreto Federal no 1.282, de 19 de outubro de 1994. Regulamenta os arts. 15, 19, 20 e 21 da Lei n⿳0 4.771, de 15 de setembro de 1965, e dá outras providências. Disponível em: http://www. jusbrasil.com.br/legislacao/109608/decreto-1282-94. Acessado em: 10.10.2011.

BRASIL. Portaria Federal IBAMA n 48, de 10 de julho de 1995. Regulamenta o Decreto 1.282, de 19 de outubro de 1994. Disponível em: http://www.ibama.gov.br/flores/leis/leis.html. Acessado em: 24.10.2010

BRASIL. Decreto Federal n ${ }^{\circ}$ 2.788, de 28 de setembro de 1998. Altera dispositivos do Decreto 1.282. Disponível em: <http://www.jusbrasil.com.br/legislacao/109609/decreto-2788-98>. Acessado em: 27.03.2011

BRASIL. Instrução Normativa Federal MMA n 4 , de 4 de março de 2002. Disponível em: http:// www.agencia.cnptia.embrapa.br/Repositorio/in_04_02_000h02byqz102wx7ha07d3364rx91vuv. pdf. Acessado em: 11.11.11

BRASIL. Ministério do Meio Ambiente. Instituto Brasileiro do Meio ambiente e Recursos Naturais Renováveis. Normas Florestais Federais para a Amazônia - Brasília: IBAMA/Diretoria de Uso Sustentável da Biodiversidade e Florestas, 2007. 176p.

BRASIL. Resolução Federal CONAMA n 406, de 02 de fevereiro de 2009. Estabelece parâmetros técnicos a serem adotados na elaboração, apresentação, avaliação técnica e execução de PMFS. Disponível em: http://www.mma.gov.br/port/conama/legiabre.cfm?codlegi=597. Acessado em: 25.02.2012

BRASIL. Decreto Federal no 6.874, de 05 de junho de 2009. Institui, no âmbito dos Ministérios do Meio Ambiente e do Desenvolvimento Agrário, o PMFCF. Disponível em: <http://www.planalto. gov.br/ccivil_03/_Ato2007-2010/2009/Decreto/D6874.htm>. Acessado em: 30.03.2012

BRASIL. Ministério do Meio Ambiente. Serviço Florestal Brasileiro. Plano anual de manejo florestal comunitário e familiar: período 2011. - Serviço Florestal Brasileiro. - Brasília: SFB, 2010. 148 p. : Il.; $30 \mathrm{~cm}$

BRASIL. Presidência da República, Casa Civil. LEI NNo 12.651, DE 25 DE MAIO DE 2012. Dispõe sobre a proteção da vegetação nativa; ... ; e dá outras providências.

CARVALHO, R. da S.; OLIVEIRA, A. D. de. Economic feasibility of timber managment in extractive settlement projects of southwestern Amazonia. Cerne, Lavras, v. 16, n. 4, p. 505-516, out/dez. 2010

CONFERÊNCIA DAS NAÇÕES UNIDAS PARA MEIO AMBIENTE E DESENVOLVIMENTO SUSTENTÁVEL (CNUMAD), 1992. Agenda 21. Disponível em: http://www.ecolnews.com.br/ agenda21/. Acesso em: 20/03/2012

CUNHA, L. H. Da “tragédia dos comuns” à ecologia política: perspectivas analíticas para o manejo comunitário dos recursos naturais. Raízes, Campina Grande, v. 23, n. 1 e 2, p. 10-26, jan/ dez. 2004

FIALHO, J. T. et al. A influência do ambientalismo na política florestal produtiva: uma percepção dos atores sociais da cadeia produtiva da madeira do Paraná. Floresta, Curitiba, PR, v.39, p 577595, jul/set. 2009.

HAJJAR, R. et al. Framing community forestry challenges with a broader lens: case studies from Brazilian Amazon. Journal of Environmental Management, Elsevier, v. 92, p. 2159-2169, 2011.

HUMPHRIES, S.; HOLMES, T. P.; KAINER, K.; KOURY, C. G. G.; CRUZ, E.; ROCHA, R. M. Are community-based forest enterprises in the tropics financially viable? Case studies from the 
Brazilian Amazon. Ecological Economics, Amsterdã, v. 77, n.4 p. 62-73, Apr. 2012

INISTITUTO BRASILEIRO DO MEIO AMBIENTE E RECURSOS NATURAIS RENOVÁVEIS. Projeto de Apoio ao Manejo Florestal Sustentável na Amazônia. Relatório de Atividades. Manaus, Am, Brasil, 2007. 113p.

INISTITUTO BRASILEIRO DO MEIO AMBIENTE E RECURSOS NATURAIS RENOVÁVEIS. Projeto Floresta em Pé. Análise e elaboração de propostas de diretrizes técnicas para elaboração e execução de planos de manejo florestal por produtores na forma individual, familiar ou comunitária, integrando produtos madeireiros e não madeireiros. Brasília, 2009. 75p. Disponível em: http://www.florestaempe.com.br/wp-content/uploads/2010/08/produto_2.pdf. Acessado em: 08.02.2012

INSTITUTO DE MANEJO E CERTIFICAÇÃO FLORESTAL E AGRÍCOLA. Agenda 21 da Vila Manaus / Comunidade da Vila Manaus - Boa Vista do Ramos. Imaflora, São Paulo. 2002. 75p.

KIBLER, J. F.; SILVA, L. N. da. Articulação nacional e internacional no Projeto Floresta Viva. T \& C Amazônia, Manaus. Ano VI, n.15, out. 2008.

KOURY, C. G. G. Manejo florestal comunitário no baixo Amazonas: custos e entraves da produção madeireira. Dissertação de mestrado. Manaus: INPA, 2007

LUDKE, M.; ANDRÉ, M. E. D. A. Pesquisa em educação: abordagens qualitativas. São Paulo, Editora Pedagógica e Universitária, 1986. 99p.

MEDINA, G.; POKORNY, B., 2011. Avaliação financeira do manejo florestal comunitário. Novos Cadernos NAEA, Belém, v. 14, n. 2, p. 25-36, 2011.

OAKLEY, P.; CLAYTON, A. Monitoramento e avaliação do empoderamento ("empowerment"). Tradução de Zuleika Arashiroe Ricardo Dias Sameshima. São Paulo, 1º Edição Instituto Pólis, 2003. 96 p.

PECQUEUR, Bernard. O desenvolvimento territorial: uma nova abordagem dos processos de desenvolvimento para as economias do sul. Raízes, Campina Grande, vol. 24, nos 01 e 02, p. 1022, jan-dez. 2005

PEREIRA, Denys et al. Fatos Florestais da Amazônia 2010. Belém: IMAZON, 2010

POKORNY, B.; JOHNSON, J. Community forestry in the Amazon: The unsolved challenge of forests and the poor. Natural Resource Perspectives, London, n. 112, 4 p. 2008.

SIRY, J. P.; CUBBAGE, F. W.; AHMED, M. R. Sustainable forest managment: global trends and opportunities. Forest Policy and Economics, Elsevier, n. 7, issue 4, p. 551-561, maio 2005

STONE-JOVICICH, S.; AMARAL, P.; CRONKLETON, P.; FONSECA, H.; PIRES, A. Acompanhamento para manejo florestal comunitário na Reserva de Desenvolvimento Sustentável Mamirauá, Amazonas, Brasil. Bogor, CIFOR. 2007. 35 p.

SUNDERLIN, W. D. Poverty alleviation through community forestry in Cambodia, Laos, and Vietnam: An assessment of the potential. Forest Policy and Economics, Elsevier, vol. 8, issue 4, p. 386-396, jun. 2006.

WANDERLEY, M. de N. B., 1989 - Em busca da modernidade social; uma homenagem a Alexander Chayanov, IN : UNICAMP, Os camponeses tem futuro? Uma homenagem a Alexander Chayanov, 33 p. Campinas. 